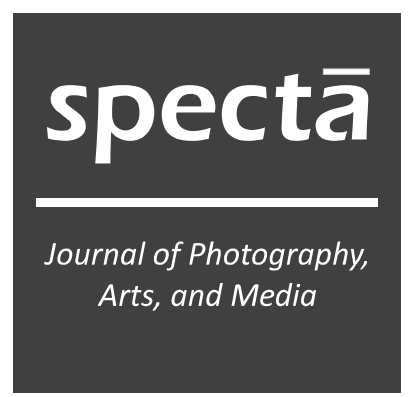

\title{
DIMENSI SPASIAL DALAM FOTOGRAFI EKSPRESI
}

Kristoforus Agung

Mahendradewa Suminto*

Arti Wulandari**

Fakultas Seni Media Rekam, Institut Seni Indonesia (ISI) Yogyakarta

Surel: mahendrads@gmail.com

Volume 1 Nomor 2,

November 2017: 141-148

\begin{abstract}
Abstrak
Fotografi yang pada umumnya berfungsi sebagai alat dokumentasi telah berkembang selaras dengan kemajuan teknologi dan daya kreatif manusia. Fotografi tidak sekadar menciptakan citraan yang begitu akurat, rinci, dan objektif dalam mengapresiasikan realitas (representasi). Namun, fotografi juga memberikan dampak yang sangat luas. Fotografi menghasilkan tata bahasa baru berupa bahasa visual, dan yang paling penting adalah kemampuan membentuk etika cara pandang baru terhadap suatu kenyataan. 'Dimensi Spasial dalam Fotografi Ekspresi' adalah sebuah konsep penciptaan karya fotografi seni sebagai ungkapan ekspresi dalam merespon visualisasi jarak-ruang yang dilihat melalui pemanfaatan framing sebagai metafora terhadap keberjarakan terhadap diri sendiri, orang lain dan lingkungan. Pengembangan unsur framing dalam perwujudan karya sebagai visualisasi mengenai dimensi spasial.
\end{abstract}

Kata Kunci: dimensi spasial, fotografi ekspresi, framing

\begin{abstract}
Spatial Dimension in Fine Art Photography. Photography, which generally serves as a tool to make documentation has grown in line with advances in technology and the creative power of men. Photography is not just creating images that are accurate, detailed, and objective in appreciating reality (representation). Even more, photography also gives a very broad impact. Photography generates a new grammar in the form of visual language, and the most important thing is the ability to form a new ethical perspective on reality. Spatial Dimension in Fine Art Photography is a concept of creating photographic works of art as an expression of responding to a distance-space visualization, seen through the use of framing as a metaphor to a self-spatial, the others and the environment. Development of framing elements in the embodiment works is regarded as a visualization of spatial dimension.
\end{abstract}

Keywords: spatial dimensions, fine art photography, framing

${ }^{*}$ Dosen di Program Studi Animasi, Jurusan Film dan Televisi, Fakultas Seni Media Rekam, ISI Yogyakarta.
${ }^{*}$ Dosen di Program Studi Fotografi, Jurusan Fotografi, Fakultas Seni Media Rekam, ISI Yogyakarta 


\section{PENDAHULUAN}

Kurang lebih setelah satu setengah abad dikembangkan dan diperkenalkan, fotografi memberikan sumbangan yang sangat berarti bagi gerak kebudayaan manusia moderen sepanjang abad ke-21. Dunia fotografi merupakan revolusi dalam cara pandang manusia untuk menerjemahkan sesuatu melalui bahasa visual (the way of vision). Fotografi tidak sekadar menciptakan citraan yang begitu akurat, rinci, dan objektif dalam mengapresiasikan realitas (representasi). Namun, fotografi juga memberikan dampak yang sangat luas. Fotografi menghasilkan tata bahasa baru berupa bahasa visual, dan yang paling penting adalah kemampuan dalam membentuk etika cara pandang baru terhadap suatu kenyataan. Terlalu naif jika kita menafikan dan tidak menggeluti teknik memotret sesuai aturan fotografi yang benar. Pengingkaran terhadap perkara teknik akan menjerumuskan orang pada kedangkalan dari hasil karya fotografinya. Kemudian muncullah pertanyaan, apa perlunya mengunggulkan kecanggihan, teknik fotografi dibandingkan dengan isi atau pesan yang hadir dari selembar foto? Lantas apakah makna dari selembar foto hanya menawarkan keindahan secara fotografinya? Selain tanda-tanda rupa yang indah itu, adakah makna tersembunyi yang dapat memberikan nilai lebih terhadap proses penikmatan?

Teknik dasar dalam fotografi sangatlah berperan penting dalam setiap proses pengambilan gambar menggunakan kamera. Teknik dasar fotografi yang berupa komposisi pemanfaatan komposisi framing sebagai visualisasi dimensi spasial, menguraikan pemahaman bahwa adanya keindahan semata-mata tergantung pada pencerapan dari si pengamat itu. Kalaupun suatu benda mempunyai nilai estetisnya sendiri, hal tersebut diartikan bahwa seorang pengamat memperoleh sesuatu pengalaman estetis sebagai tanggapan terhadap benda itu.

Tujuan dari pembuatan karya fotografi "Dimensi Spasial dalam Fotografi Ekspresi", yaitu untuk memvisualkan bentuk dan rupa dari framing yang disikapi dengan cara panadang kreatif, melalui kacamata fotografi seni ke dalam rupa metafora dimensi spasial terhadap keberjarakan diri sendiri. Setelah mengeksplorasi bentuk framing yang diinginkan sesuai dengan ide, lalu merefleksikannya kembali. Dalam membuat karya foto ini digunakanlah teknik fotografi berupa komposisi, khususnya berupa framing. Manfaat dalam penciptaan fotografi yang berjudul "Dimensi Spasial dalam Fotografi Ekspresi" adalah untuk menambah wawasan para penikmat seni, khususnya para mahasiswa Jurusan Fotografi, Fakultas Seni Media Rekam yang nantinya dalam membuat karya dan untuk dapat dikembangkan lebih lanjut dalam penciptaan karya fotografi. Memperkaya ide dan wujud seni fotografi dengan materi subjek yang sederhana. Memberikan penghiburan kepada para penikmat seni.

Kemunculan ide dasar dalam penciptaan karya ini dari sebuah perenungan, sehingga lebih bisa melihat bagaimana sesuatu hal yang ada di muka bumi ini dari barbagai sudut yang benar-benar menarik. Secara khusus melalui fotografi sendiri kita diajarkan tentang bagaimana melihat yang sesungguhnya. Sebab fotografi itu sendiri adalah ilmu yang mengajarkan tentang bagaimana melihat dengan merasakan. Fotografi ekspresi menjadi wahana untuk mengungkapkan dirinya bagi para fotografer yang mencirikan akan kediriannya melalui medium foto, ekspresi diri yang tercirikan dalan sebuah karya foto menjadi pencarian identitas pribadi. Menurut Soedjono ekspresi diri melalui medium fotografi ekspresi bisa dicapai dengan berbagai cara, diantaranya:

Memilih objek-objek foto yang unik untuk ditampilkan menjadi karya foto yang 'one of a kind'; 
penggunaan teknik khusus baik dalam pemotretan maupun dengan teknik kamar gelap, merupakan satu cara yang lain; dan bisa juga dengan cara tertentu dalam upaya menampilkan karyanya atau 'way of representation'(Soedjono, 2007:10).

Konsep perwujudan karya penciptaan ini dilakukan dengan menggunakan konsep framing yaitu bermain pada bentuk dan rupa dari elemen garis yang menimbulkan efek dimensi spasial. Proses pemotretan dilakukan dengan menggunakan teknik komposisi framing yang dianggap mampu merealisasikan ide visualisasi dimensi spasial. Adapun yang dimaksudkan dari rupa bentuk bidang keruangan yang berjarak (dimensi spasial), secara pengungkapannya sebagai sebuah metafora terhadap adanya keberjarakan antara diri sendiri, lingkungan, dan sesama. Keberjarakan ini dimaksudkan dari adanya jarak, di mana belum dan tidak mengenal satu sama lain (kecenderungan menutup diri).

Dalam proses perwujudan karya ini digunakanlah framing, yang dapat memberi efek dimensi spasial. Efek dimensi spasial merupakan visual yang terlihat melalui komposisi framing, dimana komposisi framing sendiri merupakan pengisolasian objek dengan menggunakan bingkai pengelihatan (visual), sehingga mampu memberikan efek ruang berupa kedalaman dan terasa bahwa foto itu berkesan tampak natural seperti mata melihat objek tertentu secara langsung. Komposisi framing digunakan dalam proses penciptaan fotografi ini, merupakan suatu eksplorasi bentuk atau rupa objek yang sedemikian rupa hinga menghasilkan suatu pandangan baru dalam karya visual. Melalui komposisi (permainan unsur-unsur pembentuk), kita memilih apa yang sebaiknya dimasukan ke dalam frame.

Objek utama dalam perwujudan ini merupakan upaya mengeksplorasi berbagai bentuk atau berbagai rupa framing (jendela, pintu, pagar, dinding, dan lain-lain). Dalam hal ini lebih pada ekplorasi berupa bidangbidang geometris yang mengisolasi atau membatasi bidang lain (objek pendukung). Sebab objek pendukung ini tidak dapat lepas dari pengamatan, berupa mood atau suasana. Penciptaan fotografi ini memang menjadi satu kesatuan yang utuh dan yang dengan sengaja membangun persepsi dimensi spasial dengan menggunakan teknik fotografi dasar berupa komposisi framing, dan yang di-framing berupa suasana.

Proses perwujudan tahap akhir melalui penyeleksian setiap foto dan pengeditan melalui software Adobe Photoshop CS 6. Pengeditan dilakukan sebatas pengaturan kontras (curve, burn and dodge, gradientmap) dan cropping hal ini bertujuan untuk menambah nilai estetis, dramatisasi dalam penyajian penciptaan karya foto. Hasil pengolahan foto melalui software Adobe Photoshop CS 6 kemudian dicetak $60 \mathrm{~cm} \times 40 \mathrm{~cm}$ dan $90 \mathrm{~cm} \times 60 \mathrm{~cm}$ sebagai penyajian akhir.

Sebelum melakukan proses pembuatan karya perlu ditinjau beberapa karya yang menjadi acuan dalam pembuatan fotografi ini. Ada tiga fotografer yang memberi pengaruh dalam pembuatan karya, yaitu Roman Lorang, Schmölz K.H., dan Josef Sudek.

Roman Lorang melakukan eksplorasi (gambar 1) terhadap komposisi framing yang menempatkan elemen garis sebagai objek utama dengan membingkai pemandangan

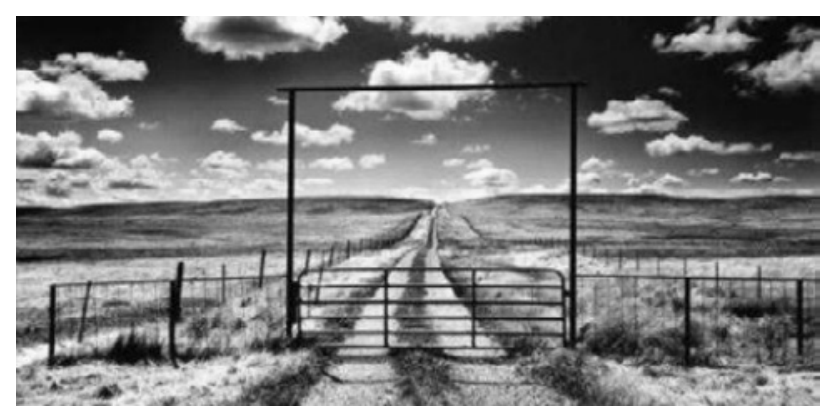

Gambar 1. Foto Acuan Karya Roman Lorang, "Fractal Dreams” (Focus Magazine, 2011:91) 
alam berupa jalan dan padang rumput. Melalui foto acuan di atas unsur framing yang ingin dieklporasi ke dalam proses perwujudan karya fotografi ini akan digunakan untuk mengeksplorasi garis sebagai unsur utama dalam pembentukan komposisi framing.

Schmölz (gambar 2) memanfaatkan jendela sebuah ruang untuk membingkai objek pelengkap yang berada di luar bangunan. Melalui foto acuan di atas bentuk framing yang ingin dieklporasi ke dalam proses perwujudan karya fotografi kali ini. Hal serupa pun akan dilakukan dengan mengeksplorasi bentuk framing dari jendela, pintu, pagar, dan lain sebagainya.

Sudek memanfaatkan jendela (gambar 3) sebuah ruang untuk membingkai objek pelengkap yang berada di dalam bangunan. Foto acuan di atas juga digunakan untuk mengeksplorasi framing dari jendela, pintu, pagar, dan

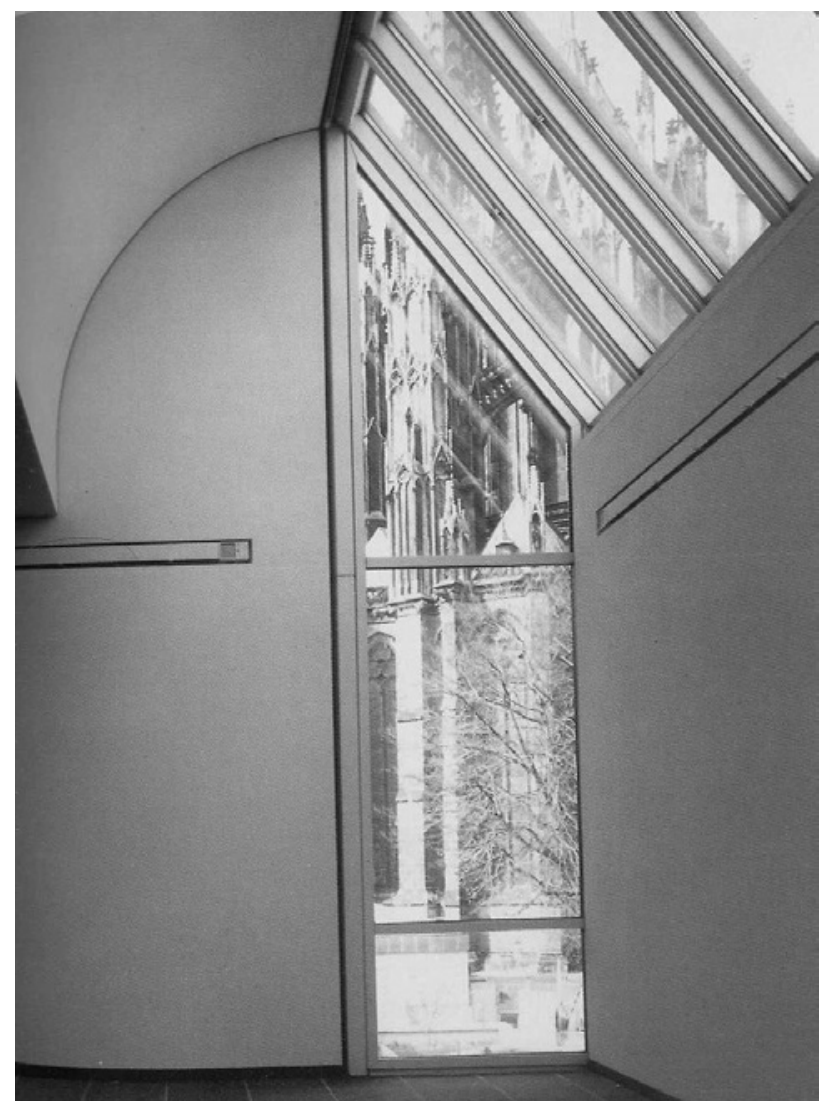

Gambar 2. Foto Acuan, Karya Schmölz K.H. (20th Century Photography, 2000:605) lain sebagainya. Karya fotografer tersebut memberikan pengaruh dalam mewujudkan karya foto "dimensi spasial sebagai metafora keberjarakan diri melalui medium fotografi ekspresi”.

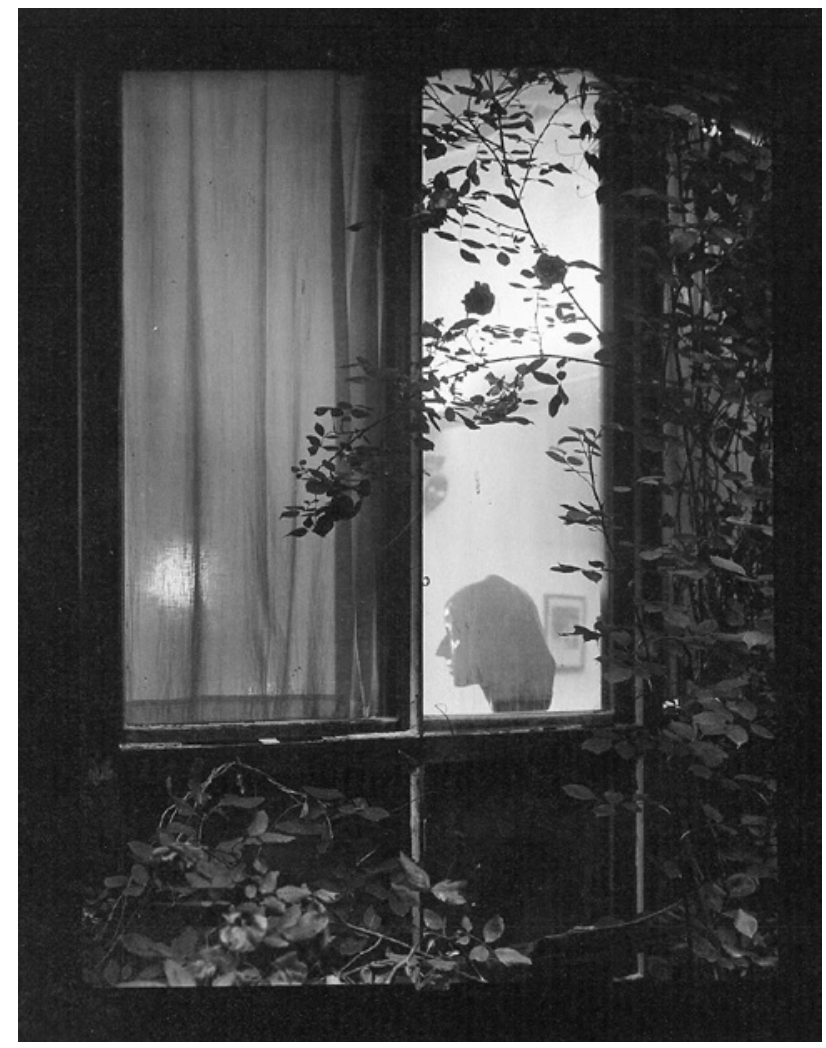

Gambar 3. Foto Acuan, Josef Sudek, "Windows From My Studio" (Mora, 2010:68)

\section{PEMBAHASAN}

Berikut ini penjelasan visualisasi dimensi spasial dalam karya fotografi. gambar 4 menunjukan penggambaran terhadap pembatasan yang dilakukan dengan secara sadar dan direncanakan. Namun, pembatasan yang dilakukan untuk menutup diri dari lingkungan luar (hal pribadi dan hal publik; personal). Sama halnya dengan pribadi seseorang yang secara sadar dan sengaja untuk menutup diri atau menarik dirinya dari pengaruh luar dengan pembatas yang telah disiapkannya, walau itu terkesan seadanya. Ketika batasan itu mulai ada celah dia akan menutupinya dengan yang baru, yang membuat dirinya merasa nyaman dan aman. 


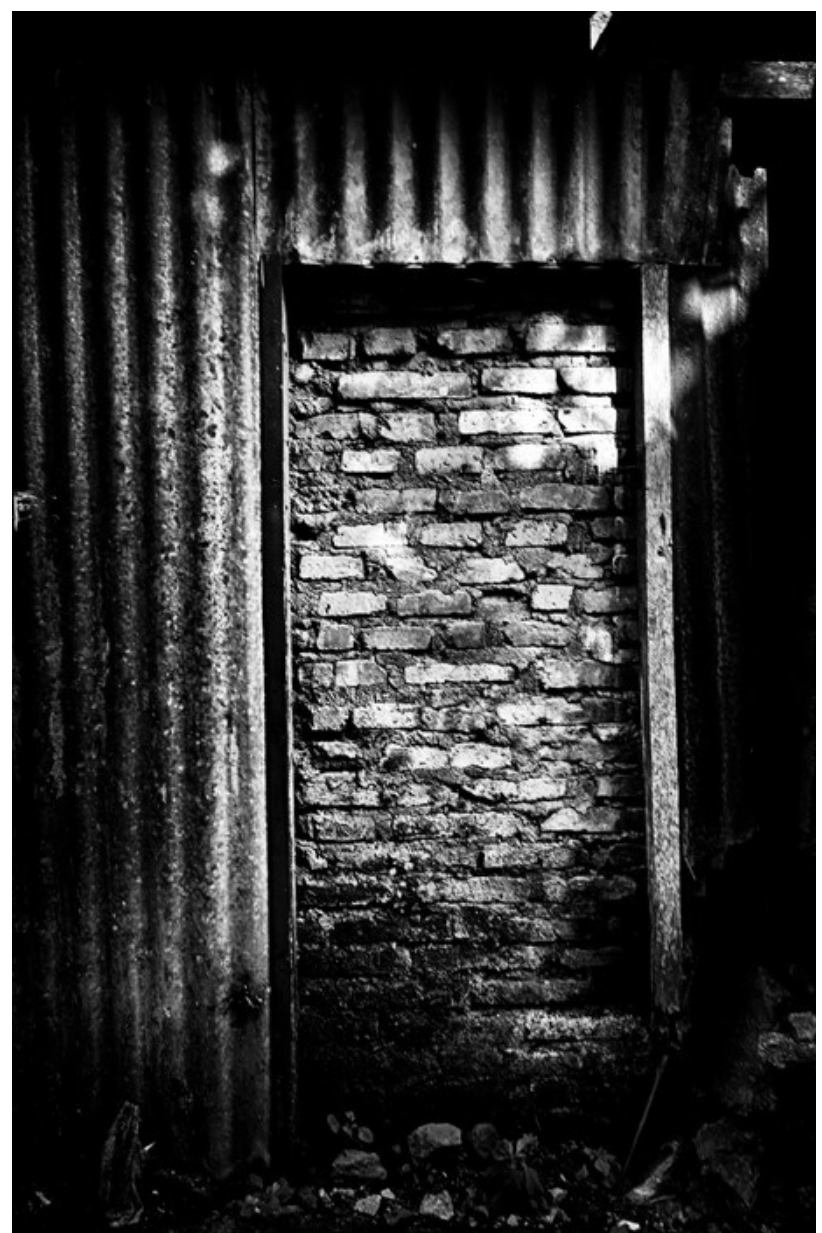

Gambar 4. "Ditutup”, 60x40cm, (2015).

Selanjutnya (gambar 5) pintu kecil menuju bangunan lain yang berlapis-lapis pintu masuknya. Membuat setiap orang atau siapa saja yang masuk ataupun ingin masuk harus melewati lapisan-lapisan pintu yang mengisolasinya dari keriuhan yang ada di luar. Membukanya pun hanya bisa dilakukan dari dalam. Demikian juga dengan kita, untuk kita masuk ke dalam diri saja perlu melawati beberapa tahapan dan setiap tahapan itu mengasingkan kita dari dunia luar serta dari dunia kasar. Sebab yang ada di dalam itu terisolasi oleh keriuhan dunia luar dan dunia kasar. Mengenal diri atau pribadi sendiri itu hal yang paling sulit dan tidak semua dari kita yang mengenal secara utuh diri atau pribadi kita.

Berbicara terang benderang dari dunia luar itu memang membutakan siapa saja, membuat lupa akan dirinya sendiri. Secercah

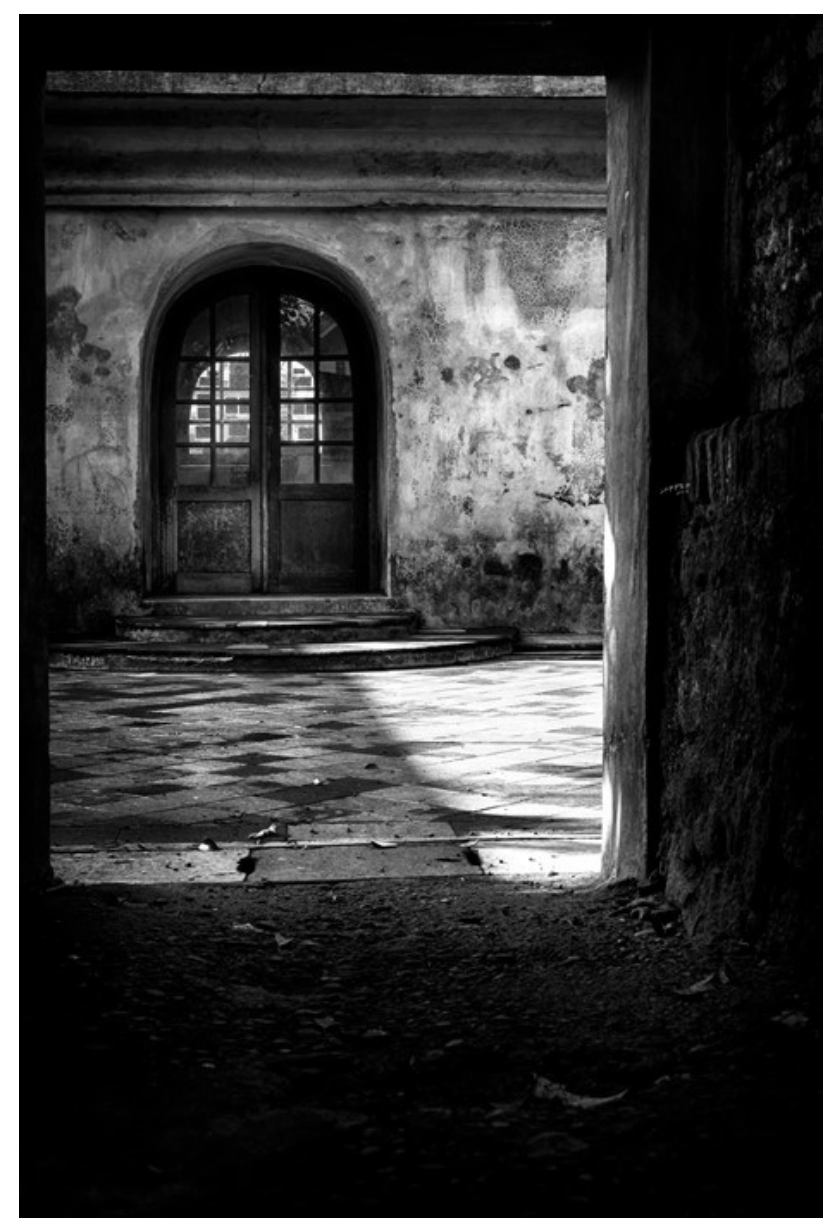

Gambar 5. "Terasing”, 60x40cm, (2015).

kemilau yang menggoda siapa saja untuk terbuai ke dalam duniannya. Dunia material (fisik) memikat siapa saja yang lengah dan tak mengenal dirinya, bahkan yang ragu untuk mengenal dirinya hingga terjerumus dalam perangkat kenikmatan semu. Barang siapa tidak mengenal dirinya dengan sebaik mungkin dia tidak akan mengenal orang lain dengan baik pula. Segala hal yang terpancar dari luar sejatinya cerminan dari yang ada di dalam dirinya. Hingga kenalilah dirimu dengan sebaik mungkin untuk mampu mengenali diri / pribadi orang lain dengan baik seperti kita yang mengenal diri/pibadi kita sendiri. (lihat gambar 6, 7 , dan 8)

Mengingatkan kembali perasaan yang ada ketika dihadapkan pada sebuah rumah. Menggali situasi, kondisi, dan peranan kita sebagai penghuni rumah. Setiap rumah pasti memiliki sambutannya sendiri terhadap penghuninya, baik itu sebagai ayah, ibu, 


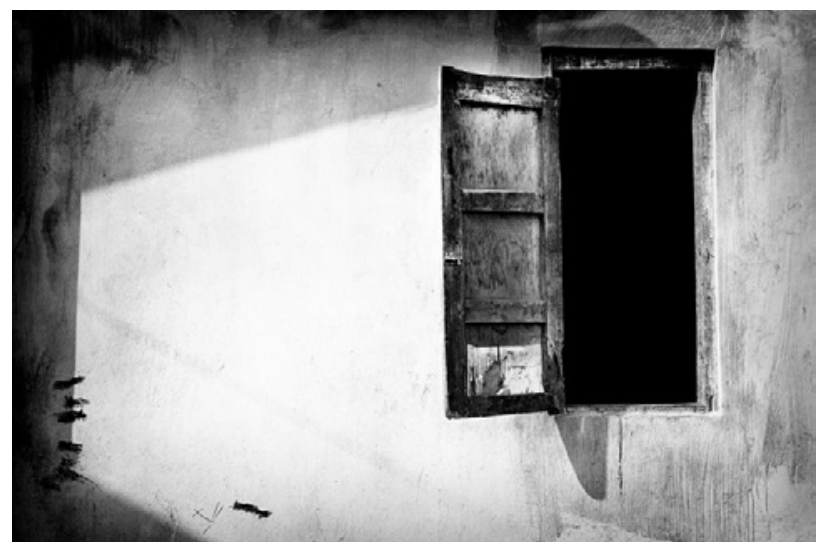

Gambar 6. "Ruang Gelap”, 90 x 60 cm, (2015).

anak, kakak, adik, kerabat, dan asisten rumah tangga. Sambutan khas di rumah membuat kita menyikapi dengan kerinduan, kemarahan, bahkan kebencian untuk kembali ke dalam rumah. Setiap diri adalah rumah bagi dirinya sendiri tak luput juga, orang tua adalah rumah bagi anak-anaknya. Rumah mempunyai peranan yang sangat vital bagi kita untuk bersosialisasi dengan yang lebih luas lagi cakupannya. Bagaimana kita di dalam rumah, bagaimana kita mengambil sikap di dalam rumah sebagai salah satu bekal yang kita bawa untuk bersosialisasi dengan komunitas yang lebih besar.

Terlampau menutup atau menarik diri ke dalam juga tidak baik. Seimbang dan selaras dalam mengambil sebuah sikap, menarik diri dari dunia luar seperti tinggal di dalam goa. Pancarkan apa yang ada di dalam diri, keluarlah dengan penuh keyakinan tanpa pernah sedikitpun merasakan keraguan. Siapa yang akan mengenal kita kalau kita menarik

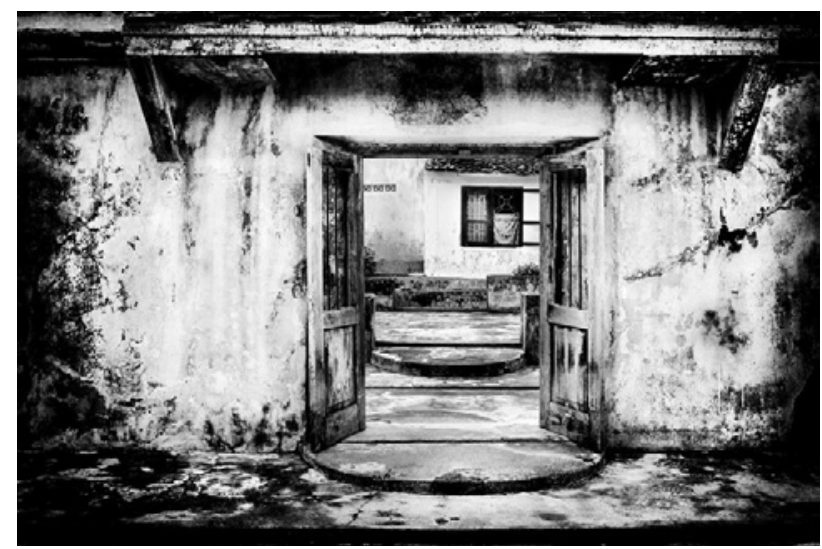

Gambar 7. "Sambutan Rumah”, 90 x 60 cm, (2015).

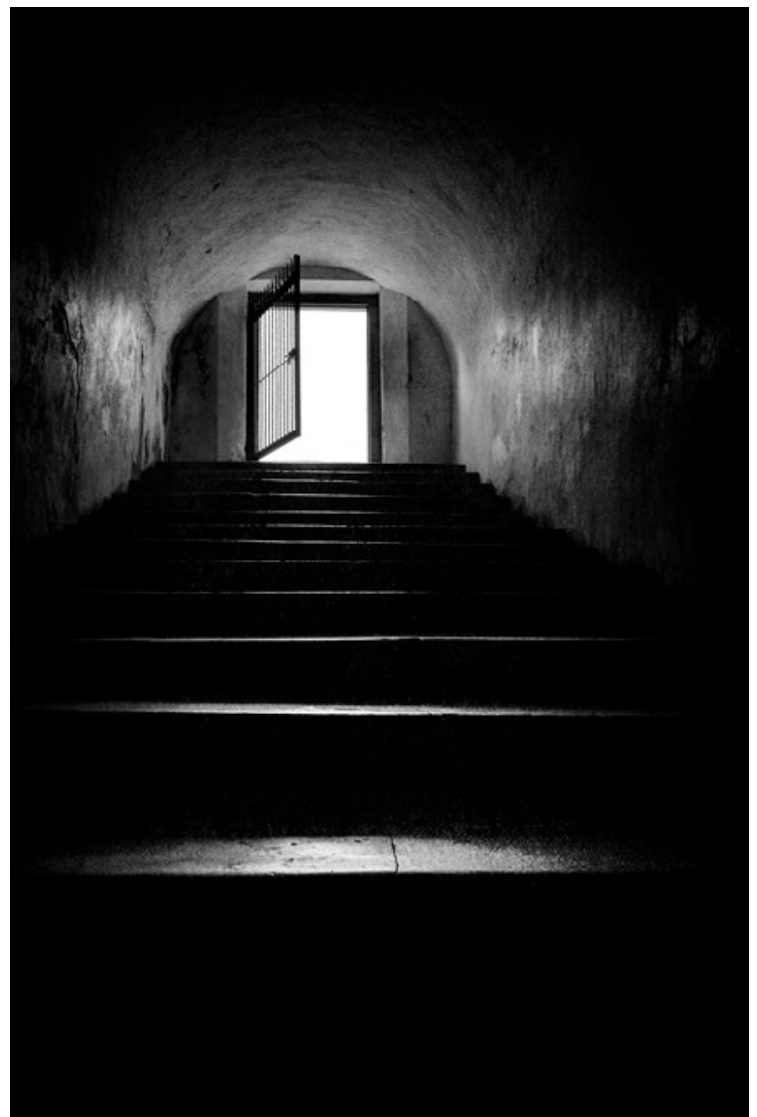

Gambar 8. “Terbukalah”, 60 x 40 cm, (2015).

diri dari dunia luar? Lantas apa guna kita terlempar ke dunia? Bukankah setiap kita adalah unik adanya, maka tunjukan setiap keunikan kita dengan menerima keunikan dari orang lain (di luar diri). Terbukalah untuk setiap perubahan dan merubah, pilihannya hanya dua yakni, mengubah atau diubah; dinamis atau statis. Bagaimana kita dapat diterima oleh orang lain kalau kita saja tidak menerima orang lain.

\section{SIMPULAN}

Fotografi adalah bagian dari alat komunikasi, berupa pesan-pesan visual. Jika kita hanya mampu memotret sesuai panduan buku manual, itu artinya kemampuan kita baru sebagai operator kamera digital. Fotografi sebagai perilaku dasar dalam melihat segala hal, dijadikan sebagai salah satu cara mewujudkan karya seni. Penciptaan ini lebih menekankan pada, bentuk serta rupa framing yang terdapat pada keseharian yang 
ada berdampingan dengan sadar maupun tidak sadar. Penggunaan framing sebagai visualisasi merupakan salah satu hal yang tak dapat terpisahkan, hingga dirasa perlu adanya pengenalan terhadap framing yang ada dalam dinamika kehidupan keseharian kita. Kemudian, fotografi dalam peranannya dijadikan sebagai medium untuk penyampaian sesuatu melalui sebuah gambar.

Keterikatan kita pada batas tidak akan terelakan sebab kita masih berada pada dunia fisik. Batasan dalam rupa framing ini tak hanya berbentuk secara nyata saja (terindra), juga yang perlu disadari kehadiran bentuk framing yang tidak terindra. Dalam keseharian, kita tidak pernah terlepas dari framing apapun itu bentuknya. Penciptaan karya Dimensi Spasial dalam Fotografi Ekspresi adalah proses kreatif dalam melihat dan menanggapi fenomena yang sangat dekat dalam keseharian, bahkan secara tidak sadar melekat pada tiap-tiap kita Penciptaan karya Dimensi Spasial dalam Fotografi Ekspresi tidak berhenti pada seputar teknik semata, tetapi bagaimana melalui teknik dasar dapat berkembang dengan menekankan pada daya kreatif. Memotret dan membuat foto indah adalah dua hal yang berbeda. Orang bisa menulis dan merangkaikan kata menjadi kalimat, bukan berarti dia dapat membuat puisi yang indah. Orang bisa menorehkan kuas dalam selembar kanvas, tidaklah berarti dia mampu membuat lukisan. Demikian juga dengan memotret dan membuat foto indah. Dibutuhkan kemampuan kreatif dalam membuat foto indah, dan tidak hanya sekedar menekan tombol shutter sebab kita bukan operator, bukan mesin.

\section{KEPUSTAKAAN}

\section{Buku}

Batdorff, John. Lauriel Exell, dkk. Komposisi Dari Foto Biasa Jadi Luar Biasa. Jakarta: Kompas Gramedia. 2013.

Borigas M., Fransiskus. ManusiaPengembara: Refleksi Filosofis Tentang Manusia. Yogyakarta: Jalasutra. 2013.

Chris, Maher, Gregory Georges, dan Larry Berman. 50 Fast Digital Camera Techniques. Indianapolis: Wiley Publishing, Inc. 2003.

la Grange, Ashley. Basic Critical Theory for Photographers. London: Focal Press. 2005.

Mora, Gilles. Photo Speak. New York: Abbeville Press. 2010.

Rosenblum, Naomi.. A World History of Photography. New York: Abbeville Press. 1984

Sibley, Norman dan Michael F. O'Brian. The Photographic Eye. Worcester: Davis Publication, Inc. 1995.

Soedjono, Soeprapto. Pot-Pourri Fotografi. Jakarta: Universitas Trisakti. 2006.

Sp., Soedarso. Trilogi Seni: Penciptaan, Eksistensi, dan Kegunaan Seni. Yogyakarta: BP ISI Yogyakarta. 2006.

Sumardjono, Jakob. Filsafat Seni. Bandung: Penerbit ITB. 2000.

Sumaryono, E. Hermeneutik: Sebuah Metode Filsafat. Yogyakarta: Kanisius. 1993.

Sunardi, ST., Semiotika Negativa. Yogyakarta: Buku Baik. 2002.

Svarajati, Tubagus P. Phōtagōgós: TerangGelap Fotografi Indonesia. Semarang: Suka Buku. 2013. 